\title{
Global Obesity Study on Drivers for Weight Reduction Strategies
}

\author{
Carola Grebitus $^{a} \quad$ Monika Hartmann ${ }^{b} \quad$ Nikolai Reynolds ${ }^{c}$ \\ ${ }^{a}$ Arizona State University|W. P. Carey School of Business, Morrison School of Agribusiness, \\ Mesa, AZ, USA; ${ }^{b}$ Institute for Food and Resource Economics, Rheinische Friedrich-Wilhelms- \\ Universität Bonn, Bonn, Germany; ${ }^{C}$ Ipsos InnoQuest and Health Care Germany, Hamburg, \\ Germany
}

\section{Key Words}

Cross-country survey $\cdot$ Weight reduction strategy · Dietary change $\cdot$ Physical activity . National differences

\begin{abstract}
Objective: To assess factors determining the reaction of individuals to the threats of overweight and obesity and to examine the interdependencies between weight-reducing strategies. Methods: Cross-country survey covering 19 countries and 13,155 interviews. Data were analysed using a bivariate probit model that allows simultaneously analysing two weight-reducing strategies. Results: Results show that weight-reducing strategies chosen are not independent from each other. Findings also reveal that different strategies are chosen by different population segments. Women are more likely to change their dietary patterns and less likely to become physically active after surpassing a weight threshold. In addition, the probability of a dietary change in case of overweight differs considerably between countries. The study also reveals that attitudes are an important factor for the strategy choice. Conclusions: It is vital for public health policies to understand determinants of citizens' engagement in weight reduction strategies once a certain threshold is reached. Thus, results can support the design of public health campaigns and programmes that aim to change community or national health behaviour trends taking into account, e.g., national differences.

(c) 2015 S. Karger GmbH, Freiburg
\end{abstract}

\section{Introduction}

The worldwide prevalence of obesity has nearly doubled between 1980 and 2008. For 2008, the World Health Organization (WHO) estimated that globally about 35\% of adults aged 20 years and above were overweight and $12 \%$ were obese [1]. Overweight is defined as 
a BMI (= body weight in kilograms divided by height in meters squared) greater than 25 and obesity starts if the BMI exceeds 30 . The pervasiveness of obesity is no longer a phenomenon of western high-income countries but is as well on the rise in low- and middle-income countries [1]. This worldwide epidemic prompts detrimental consequences for individuals and societies. There exists ample scientific evidence that obesity decreases health-related quality of life and overall life expectancy [2]. The death of more than 2.8 million people annually is linked to overweight and obesity [1]. With a raise in BMI, the risks of coronary artery disease, strokes, hypertension, osteoarthritis, asthma, depression, type 2 diabetes and various forms of cancer increases [3]. The respective burden for the health care system is tremendous. Cawleya and Meyerhoefer [4] show for the USA that the annual cost of treating obesity amount to $16.5 \%$ of the national spending on medical care, though these relative high estimates are not supported by most other studies [5]. However, the costs of obesity are in any case not only reflected in increased expenditures for the health system. Additional costs accrue to the individual and the society due to a loss of economic efficiency resulting from lower returns on education, higher level of absenteeism and presenteeism, lower household wages and incomes, increased premature retirement and unemployment as well as higher dependence on welfare $[6,7]$.

The economic, social and psychological consequences of diet-related health risks may induce responses at the level of institutions such as the government, non-governmental agencies, media and industry. In addition, reaction to the threat of obesity might also occur at the level of the individual affected by those health risks. To remain a healthy weight or fight overweight and obesity, individuals may regularly control their weight, be physically active or secure a healthy diet, the latter with or without seeking external advice. In order to better communicate health messages related to overweight and obesity, it is important to better understand those different strategies.

This paper contributes to the literature by analysing first what strategies people use to maintain or reduce body weight. Second, the paper provides insights regarding the factors determining the strategy choice as well as the interdependencies between strategies. Those include body consciousness measured by frequency of weighing, gender, nationality to account for cultural differences and attitudes towards food, diets and food industry. To collect data, a global survey on fitness, weight control and attitudes towards food and health was conducted in 19 countries. Results lend support to designing public health campaigns and programmes that aim to change community or national health behaviour trends taking into account national differences.

\section{Material and Methods}

\section{Data Set}

In this study, a unique data set is used. Citizen data were collected via Omnibus approach (short survey covering efficiently multiple topics) from the general population across 19 countries from March to July 2010 by the market research company Synovate (today Synovate is part of Ipsos). For this study, survey participants were asked the questions depicted in the supplemental material (available at http://content. karger.com/ProdukteDB/produkte.asp?doi=373905). The countries were specifically selected to provide a regional perspective around the globe. With Argentina, Brazil, Canada, Chile, China, Colombia, Denmark, Egypt, India, Indonesia, South Korea, the Netherlands, Romania, Russia, Saudi Arabia, Singapore, Turkey, UK and USA, the sample covers high-, medium- and low-income countries. For each country, the Omnibus was conducted using sampling methods and survey modes according to the requirements of the respective countries (e.g. computer-assisted telephone interview; CATI), whilst still allowing comparability across countries. As the general population should be considered, no specific screening questions were implemented 
Grebitus et al.: Global Obesity Study on Drivers for Weight Reduction Strategies

Table 1. Dependent variable description

\begin{tabular}{|c|c|c|c|c|c|}
\hline Variable & Description & Mean & SD & Min & Max \\
\hline Physical activity & $\begin{array}{l}\text { Dummy variable equal to } 1 \text { if respondents answer that } \\
\text { they react to weight increase by physical activity, } 0 \text { if } \\
\text { otherwise }\end{array}$ & 0.36 & 0.48 & 0 & 1 \\
\hline Dietary change & $\begin{array}{l}\text { Dummy variable equal to } 1 \text { if respondents answer that } \\
\text { at least one of the following options is used as reaction } \\
\text { to weight increase, } 0 \text { if otherwise: reduce food intake; } \\
\text { change types of foods that you eat; reduce softdrinks; } \\
\text { have a bit every } 3 \text { hours; increase water intake; watch } \\
\text { what I eat; drink more water; leave out some foods } \\
\text { (bread, candies) }\end{array}$ & 0.52 & 0.50 & 0 & 1 \\
\hline
\end{tabular}

$\mathrm{SD}=$ Standard deviation; Min = minimum; $\mathrm{Max}=$ maximum .

on weight behaviour. The respondents were randomly selected either through street recruitment, through Synovate's Online Panel or phone book depending on the requirements of the countries. Representativeness was provided through random sampling modes and cross-referencing distribution with national statistics. An average response rate of $40 \%$ resulted in 13,155 responses. Data collected included questions on fitness, weight control and attitudes towards food and health. Due to missing values, the number of observations in the empirical analyses is reduced to 11,955 respondents. The number of responses per country (n) were as follows: Argentina $n=300$, Brazil $n=600$, Canada $n=1,023$, Chile $n=500$, China $n=1,006$, Colombia $n=$ 485 , Denmark $n=478$, Egypt $n=322$, India $n=509$, Indonesia $n=1,054$, South Korea 501, the Netherlands $n=1,125$, Romania $n=1,500$, Saudi Arabia $n=538$, Singapore $n=507$, Turkey $n=500$, UK $n=502$, USA $\mathrm{n}=505$.

\section{Descriptive Analysis of Factors Influencing Choice of Weight Reduction Strategies}

\section{Choice of Weight Reduction Strategies (Dependent Variables)}

To find out what people do to get themselves back on track when gaining weight, the multiple response question 'Do you take any of the following steps when you feel your weight goes beyond a certain threshold?' was considered. Possible answers were i) related to physical activity (increase physical activity), ii) dietary change (take herbs or supplements which promise weight loss, attend Weightwatchers meetings, reduce food intake, change types of foods eaten, reduce soda/ soft drinks, have a bite every $3 \mathrm{~h}$, increase water intake, watch what I eat, drink more water, leave out some foods (bread, candies)), iii) easy adjustments (go to the doctor, take a massage to lose weight, acupuncture to lose weight, and iv) none of these. Participants were asked to check all that apply. The top three responses overall were 'reduce food intake' accounting for $40 \%$ of the answers, 'increase physical activity' with $35 \%$ and 'change types of food that you eat' with $25 \%$. The answers per overall category were distributed as follows: $36 \%$ of responses were accumulated for 'physical activity', 52\% for 'dietary change' and 6\% for 'easy adjustments'. With regard to the distribution of the responses, in this study we will concentrate on the former two. Also, physical activity and a healthy diet are key determinants of securing energy balance and thus weight control [8], while 'easy adjustments' by itself will not lead to a sustainable weight loss. The variables were coded as dummy variables equal to one if the respondent answered positively to at least one of the statements in the respective category. Table 1 depicts the variable description of dependent variables.

Table 2 displays the cross-tabulated weight loss strategies of physical activities and dietary change. According to this table, $36 \%$ neither change their diets nor start being physically active, $24 \%$ use both strategies to lose weight, $12 \%$ are physically active without any dietary change, and $28 \%$ change their diets without being physically active at all. 
Grebitus et al.: Global Obesity Study on Drivers for Weight Reduction Strategies

Table 2. Dependent variable description - cross-tabulation

\begin{tabular}{llll}
\hline \multirow{2}{*}{ Dietary change } & \multicolumn{3}{l}{ Physical activity, \% } \\
\cline { 2 - 4 } & no & yes & total \\
\hline No & 36.17 & 11.70 & 47.87 \\
Yes & 27.70 & 24.43 & 52.13 \\
Total & 63.86 & 36.14 & 100 \\
\hline
\end{tabular}

Attitudes, Gender and Nationality: Factors Determining Choice of Weight Reduction Strategies (Independent Variables)

Food is more than a functional transaction which we undertake to keep ourselves going. Food is linked to pleasure and has cultural and social meaning [9]. Thus, we account for attitudes towards eating and eating habits. About one third of respondents (29\%) surveyed across the 19 markets admitted to liking the taste of fast food too much to give it up. Eating the 'wrong' things can also be perceived as comforting. In this regard, $26 \%$ of respondents indicate to eat junk food when feeling down. Conversely, $84 \%$ of the sample agrees that eating healthy food makes themselves feel better while $69 \%$ watch their food intake carefully and strive to be healthy. Over one third (32\%) of all respondents is worried about the issue of childhood obesity in their own home, whereas $58 \%$ are worried about the issue of childhood obesity in their country. Overall, $61 \%$ of respondents agree that food companies can help prevent childhood obesity. Because data were collected simply by answering with yes or no (1/0 coding) we could not apply factor analysis to combine correlated items into uncorrelated factors. Instead we built naïve indices summing up statements that fit into the categories food lover (e.g., 'I like the taste of fast food too much to give it up'), healthy eater (e.g., 'healthy food makes me feel better'), worry obesity (e.g., I am worried about the issue of childhood obesity in my country') and pro food industry (e.g., 'food companies can help prevent childhood obesity'). These indices were included in the empirical analysis to measure the influence of a person's attitudes on her/his weight-reducing strategies (see table 3 for variable description).

In addition, to analyse determinants of the respective strategies, participants were asked how often they weigh themselves. This gives a first impression on peoples' health consciousness. Results show for example that $5 \%$ of respondents weigh themselves daily and $15 \%$ once a week. $35 \%$ weigh themselves whenever they remember, and one quarter of the sample claims not to weigh themselves at all.

Furthermore, gender (equally distributed among the sample) and nationality were considered as independent variables. Regarding nationality, Argentina was selected to be the reference country, thus, serving as benchmark for all other countries.

\section{Analysing Effects on Weight Reduction Strategies: Bivariate Probit Model}

Because the two dependent variables are binary variables we employ probit models to analyse determinants of weight reducing strategies. We compare two different strategies: 'dietary change' and 'physical activity', a person might pursue when (s)he feels that the body weight goes beyond a certain threshold. In this paper, a bivariate probit model is employed as it allows to simultaneously estimate the determinants for both weight-reducing strategies and to test whether the respective two equations are independent or not [10]. If the parameter rho (which is also known as the 'polychoric correlation coefficient' in the psychometric and statistical literature [11]) is significant, the bivariate probit model is preferred. Otherwise, two single univariate probit models should be chosen. A significant positive (negative) correlation coefficient rho would be evidence of the cross-equation effects and that the strategy choices are complements (substitutes). The bivariate probit model is estimated using maximum likelihood methods. As the bivariate probit model is a standard procedure, we refer the interested reader to Greene [10] for more information. 
Table 3. Independent variable description

\begin{tabular}{|c|c|c|c|c|c|}
\hline Variable & Description & Mean & SD & Min & Max \\
\hline Gender & dummy variable equal to 1 if female, 0 if otherwise & 0.50 & 0.50 & 0 & 1 \\
\hline $\begin{array}{l}\text { Frequency of } \\
\text { weighing }\end{array}$ & $\begin{array}{l}1 \text { = more than once a day, } 2=\text { daily, } 3=\text { once every few days, } 4=\text { weekly, } 5 \\
=\text { monthly, } 6=\text { whenever remember } / \text { clothes are getting tight, } 7=\text { do not } \\
\text { weigh myself }\end{array}$ & 5.40 & 1.59 & 1 & 7 \\
\hline Argentina & $\begin{array}{l}\text { reference country; dummy variable equal to } 1 \text { if respondent comes from } \\
\text { the respective country, } 0 \text { if otherwise }\end{array}$ & 0.02 & 0.15 & 0 & 1 \\
\hline Brazil & $\begin{array}{l}\text { dummy variable equal to } 1 \text { if respondent comes from the respective } \\
\text { country, } 0 \text { if otherwise }\end{array}$ & 0.05 & 0.21 & 0 & 1 \\
\hline Canada & $\begin{array}{l}\text { dummy variable equal to } 1 \text { if respondent comes from the respective } \\
\text { country, } 0 \text { if otherwise }\end{array}$ & 0.08 & 0.27 & 0 & 1 \\
\hline Columbia & $\begin{array}{l}\text { dummy variable equal to } 1 \text { if respondent comes from the respective } \\
\text { country, } 0 \text { if otherwise }\end{array}$ & 0.04 & 0.19 & 0 & 1 \\
\hline Denmark & $\begin{array}{l}\text { dummy variable equal to } 1 \text { if respondent comes from the respective } \\
\text { country, } 0 \text { if otherwise }\end{array}$ & 0.04 & 0.19 & 0 & 1 \\
\hline Egypt & $\begin{array}{l}\text { dummy variable equal to } 1 \text { if respondent comes from the respective } \\
\text { country, } 0 \text { if otherwise }\end{array}$ & 0.02 & 0.15 & 0 & 1 \\
\hline UK & $\begin{array}{l}\text { dummy variable equal to } 1 \text { if respondent comes from the respective } \\
\text { country, } 0 \text { if otherwise }\end{array}$ & 0.04 & 0.19 & 0 & 1 \\
\hline USA & $\begin{array}{l}\text { dummy variable equal to } 1 \text { if respondent comes from the respective } \\
\text { country, } 0 \text { if otherwise }\end{array}$ & 0.04 & 0.19 & 0 & 1 \\
\hline The Netherlands & $\begin{array}{l}\text { dummy variable equal to } 1 \text { if respondent comes from the respective } \\
\text { country, } 0 \text { if otherwise }\end{array}$ & 0.09 & 0.28 & 0 & 1 \\
\hline Turkey & $\begin{array}{l}\text { dummy variable equal to } 1 \text { if respondent comes from the respective } \\
\text { country, } 0 \text { if otherwise }\end{array}$ & 0.04 & 0.19 & 0 & 1 \\
\hline China & $\begin{array}{l}\text { dummy variable equal to } 1 \text { if respondent comes from the respective } \\
\text { country, } 0 \text { if otherwise }\end{array}$ & 0.08 & 0.27 & 0 & 1 \\
\hline India & $\begin{array}{l}\text { dummy variable equal to } 1 \text { if respondent comes from the respective } \\
\text { country, } 0 \text { if otherwise }\end{array}$ & 0.04 & 0.19 & 0 & 1 \\
\hline Indonesia & $\begin{array}{l}\text { dummy variable equal to } 1 \text { if respondent comes from the respective } \\
\text { country, } 0 \text { if otherwise }\end{array}$ & 0.08 & 0.27 & 0 & 1 \\
\hline South Korea & $\begin{array}{l}\text { dummy variable equal to } 1 \text { if respondent comes from the respective } \\
\text { country, } 0 \text { if otherwise }\end{array}$ & 0.04 & 0.19 & 0 & 1 \\
\hline Saudi Arabia & $\begin{array}{l}\text { dummy variable equal to } 1 \text { if respondent comes from the respective } \\
\text { country, } 0 \text { if otherwise }\end{array}$ & 0.04 & 0.20 & 0 & 1 \\
\hline Singapore & $\begin{array}{l}\text { dummy variable equal to } 1 \text { if respondent comes from the respective } \\
\text { country, } 0 \text { if otherwise }\end{array}$ & 0.04 & 0.19 & 0 & 1 \\
\hline Chile & $\begin{array}{l}\text { dummy variable equal to } 1 \text { if respondent comes from the respective } \\
\text { country, } 0 \text { if otherwise }\end{array}$ & 0.04 & 0.19 & 0 & 1 \\
\hline Romania & $\begin{array}{l}\text { dummy variable equal to } 1 \text { if respondent comes from the respective } \\
\text { country, } 0 \text { if otherwise }\end{array}$ & 0.11 & 0.32 & 0 & 1 \\
\hline Russia & $\begin{array}{l}\text { dummy variable equal to } 1 \text { if respondent comes from the respective } \\
\text { country, } 0 \text { if otherwise }\end{array}$ & 0.09 & 0.29 & 0 & 1 \\
\hline Food lover & $\begin{array}{l}\text { sum of responses for each response if yes } 1 \text {, otherwise } 0 \text { : eat whatever I } \\
\text { want, whenever I want; life is too short to deny yourself whatever you } \\
\text { want, even though it may be unhealthy; like the taste of fast food too much } \\
\text { to give it up }\end{array}$ & 1.24 & 1.01 & 0 & 3 \\
\hline Healthy eater & $\begin{array}{l}\text { sum of responses for each response if yes } 1 \text {, otherwise } 0 \text { : watch my food } \\
\text { intake carefully and strive to be healthy; healthy food makes me feel } \\
\text { better }\end{array}$ & 1.53 & 0.66 & 0 & 2 \\
\hline Worry obesity & $\begin{array}{l}\text { sum of responses for each response if yes } 1 \text {, otherwise } 0 \text { : worried about } \\
\text { issue of childhood obesity, in my own home; worried about issue of } \\
\text { childhood obesity, in my country }\end{array}$ & 0.88 & 0.79 & 0 & 2 \\
\hline Pro food industry & $\begin{array}{l}\text { sum of responses for each response if yes } 1 \text {, otherwise } 0 \text { : food companies } \\
\text { offer enough healthy food options; food companies can help prevent } \\
\text { childhood obesity }\end{array}$ & 1.06 & 0.77 & 0 & 2 \\
\hline
\end{tabular}


Table 4. Determinants of weight loss strategies

\begin{tabular}{|c|c|c|c|c|c|c|c|c|}
\hline & \multicolumn{4}{|c|}{ Dietary change } & \multicolumn{4}{|c|}{ Physical activity } \\
\hline & coefficient & $\begin{array}{l}\text { standard } \\
\text { error }\end{array}$ & z-value & & coefficient & $\begin{array}{l}\text { standard } \\
\text { error }\end{array}$ & z-value & \\
\hline Gender & 0.37 & 0.02 & 15.66 & $* * *$ & -0.15 & 0.02 & -6.14 & $* * *$ \\
\hline Frequency of weighing & -0.17 & 0.01 & -21.04 & $* * *$ & -0.1 & 0.01 & -13.18 & $* * *$ \\
\hline Brazil & -0.31 & 0.1 & -3.08 & $* * *$ & -0.16 & 0.1 & -1.63 & $*$ \\
\hline Canada & 0.06 & 0.09 & 0.61 & & 0.41 & 0.09 & 4.55 & $* * *$ \\
\hline Columbia & -0.6 & 0.11 & -5.45 & $* * *$ & -0.32 & 0.11 & -2.79 & $* * *$ \\
\hline Denmark & -0.03 & 0.1 & -0.28 & & 0.19 & 0.1 & 1.86 & $*$ \\
\hline Egypt & -0.3 & 0.11 & -2.75 & $* * *$ & 0.06 & 0.11 & 0.55 & \\
\hline UK & 0 & 0.1 & -0.05 & & 0.31 & 0.1 & 3.1 & $* * *$ \\
\hline USA & 0.13 & 0.1 & 1.23 & & 0.47 & 0.1 & 4.78 & $* * *$ \\
\hline The Netherlands & -0.32 & 0.09 & -3.59 & $* * *$ & 0.09 & 0.09 & 1.02 & \\
\hline Turkey & -0.59 & 0.1 & -6 & $* * *$ & -0.44 & 0.1 & -4.38 & $* * *$ \\
\hline China & -0.01 & 0.09 & -0.12 & & 0.54 & 0.09 & 5.99 & $* * *$ \\
\hline India & -0.85 & 0.1 & -8.52 & $* * *$ & -0.26 & 0.1 & -2.63 & $* * *$ \\
\hline Indonesia & -0.74 & 0.09 & -8.14 & $* * *$ & -0.15 & 0.09 & -1.6 & \\
\hline South Korea & -0.71 & 0.1 & -7.31 & $* * *$ & 0.15 & 0.1 & 1.5 & \\
\hline Saudi Arabia & -0.01 & 0.1 & -0.13 & & 0.02 & 0.1 & 0.17 & \\
\hline Singapore & -0.64 & 0.1 & -6.42 & $* * *$ & 0.06 & 0.1 & 0.62 & \\
\hline Chile & -0.21 & 0.1 & -2.07 & $* *$ & -0.2 & 0.1 & -1.98 & $* *$ \\
\hline Romania & -0.47 & 0.09 & -5.4 & $* * *$ & -0.3 & 0.09 & -3.35 & $* * *$ \\
\hline Russia & -0.77 & 0.09 & -8.85 & $* * *$ & -0.35 & 0.09 & -3.95 & $* * *$ \\
\hline Food lover & -0.13 & 0.01 & -10.33 & $* * *$ & -0.05 & 0.01 & -4.21 & $* * *$ \\
\hline Healthy eater & 0.14 & 0.02 & 7.02 & $* * *$ & 0.22 & 0.02 & 10.89 & $* * *$ \\
\hline Worry obesity & 0.1 & 0.02 & 6.27 & $* * *$ & 0.07 & 0.02 & 4.22 & $* * *$ \\
\hline Pro food industry & 0.03 & 0.02 & 1.59 & & 0.06 & 0.02 & 3.67 & $* * *$ \\
\hline Constant & 1.02 & 0.1 & 10.43 & $* * *$ & -0.14 & 0.1 & -1.47 & \\
\hline
\end{tabular}

Wald chi2 $(48)=2786.77$, Log pseudolikelihood $=-15235.07$, Prob $>$ chi2 $=0.00$. Asterisks indicate the level of significance at $1 \%$ for $* * *, 5 \%$ for $* *$, and $10 \%$ for *.

\section{Results}

Table 4 presents the results of the bivariate probit model analysing the determinants of two different weight reduction strategies in case a certain weight threshold is passed. As determinants for the strategy choice, we consider body consciousness measured by frequency of weighing, gender, nationality to account for cultural differences and attitudes towards food, diets and the food industry. Rather than applying two univariate probit models we use one bivariate probit model to test for possible correlation between the two strategies. Parameter rho is highly significant $(1 \%$ level, +0.27$)$, confirming that one bivariate probit model is more appropriate than two single probit models.

Table 4 also summarises the coefficient estimates that reveal the effects of explanatory variables (e.g., gender; see table 3) on the probability that citizens engage in a strategy (e.g. physical activity) to lose or maintain weight. Negative (positive) estimates indicate that an increase in the value of the explanatory variable corresponds to decreasing (increasing) probabilities. Results show that different strategies are chosen by different segments.

The coefficient of food lovers is negative regarding dietary change. This group is also less likely to become physically active as a strategy to lose weight. Having the attitude of a healthy eater or concerned citizen (worry obesity) increases the odds of pursuing both strategies to 
lose weight. A pro-industry attitude increases the probability that a person becomes more physically active if (s)he feels to be overweight.

As Argentina was selected to be the reference country, country effects have to be interpreted against Argentina. It should be noted that one of the countries had to be excluded for modelling reasons, i.e., in order to avoid multicollinearity. Any of the countries could have been selected as reference country. The results would shift accordingly in the relative comparison. Nationality proves to be significant with a negative sign for 12 of the 18 countries (Brazil, Columbia, Egypt, the Netherlands, Turkey, India, Indonesia, South Korea, Singapore, Chile, Romania and Russia), indicating that the likelihood is lower for inhabitants of those countries to change their diet when passing a weight threshold if compared to Argentines. In fact, for 7 of those countries (Brazil, Columbia, Turkey, India, Chile, Romania and Russia) also the strategy of engaging in physical activity to reduce weight is less likely than for people from Argentina. In contrast, citizens from Canada, Denmark, the UK, the USA and China have a higher probability to become active to reduce weight than this holds for Argentines.

Significant results for gender, with a positive sign in the sub-model 'dietary changes' and a negative sign in the sub-model 'physical activity' indicate that women are more likely to change their diet and reduce for example their meal size while being female reduces the odds of becoming physically active to reduce weight, i.e., male individuals are more likely to work out to reduce a weight gain.

Finally, the more often someone weights him/herself the higher the probability to apply either strategy.

\section{Discussion}

The purpose of this study was to explore the relevance of different strategies citizens use to reduce their body weight once a certain weight threshold is exceeded. In addition, we investigate the factors which determine the choice of the strategy.

\section{Relationship between the Weight Reduction Strategies}

Findings indicate that most people choose to change their dietary patterns followed by those who increase their physical activity while only a minority of respondents selects methods such as acupuncture for losing weight. The analyses based on the Bivariate Probit Model point to the complementary character of the two main strategy choices (change the diet, engage in physical activity). Thus, those citizens increasing their physical activity to lose weight are somewhat more likely to change their diet as well, once their weight exceeds a certain threshold. These results are confirmed by other studies $[12,13]$.

\section{Effect of Attitudes on Choice of a Weight Reduction Strategy}

Our results suggest that attitudes are important predictors for the weight loss strategy an individual chooses. The finding that food lovers have a low probability to change their eating habits is not surprising. In general, changing habits by influencing preferences for more healthy food is a challenging task and most promising if started at an early age $[14,15]$. Thus, school fruit programmes and school lunch programmes that follow nutritional standards may be an effective strategy to promote healthy eating behaviours [16]. Alarming is the result that the group of food lovers is also less inclined to engage in physical activities. Those, 
Grebitus et al.: Global Obesity Study on Drivers for Weight Reduction Strategies

who are aware that they 'love food too much to resist it' might feel a barrier to engage in either weight-reducing strategy. A lack of self-efficacy has been shown to contribute to the persistence of unhealthy lifestyles $[17,18]$. Nudging towards healthier eating patterns as well as towards increased physical activity might offer solutions [19]. In addition, governmental policies are needed to overcome these weight status barriers and increase the confidence of overweight/obese people that they are able to perform weight-reducing strategies

We also detected that the healthy eaters, the concerned ones and those with a pro-food industry attitude are more likely to adjust their diet and/or engage in physical activity if their weight exceeds a threshold. Those citizens could be supported by promotional and educational strategies with stronger cognitive and rational communication focus (i.e., the central route to persuasion [20]) to assure that they maintain a healthy weight through healthy eating habits and physical exercise.

\section{Effect of Nationality on Choice of a Weight Reduction Strategy}

The differences identified with respect to nationality could be helpful to initiate more targeted public health campaigns and programmes to change citizens' health behaviour. Our results reveal that the probability of a dietary change if weight surpasses a threshold is from all countries least likely to be pursued in India, followed by Russia, Indonesia, South Korea, Singapore and Turkey. For two of those countries, Turkey and Russia, a strategy of physical activity is also least likely to be pursued to fight overweight. This indicates that in those two countries a lack of reaction to the threat of obesity at the level of the individuals is present. However, Turkey and Russia belong to those countries with a relative high share of obese people (Turkey 29\%; Russia 24\% [1]). One explanation for this inertia might be that perceptions of overweight and efforts to lose weight emerge relative to local weight conditions [21]. Among an overweight population an appropriate awareness and efforts to engage in weightlosing strategies is likely more difficult to develop. Public health policies might be needed that increase the awareness regarding the detrimental health impact of obesity.

\section{Effect of Gender on Choice of a Weight Reduction Strategy}

Our findings for gender suggest that, while female are more likely to reduce weight by dietary changes, the preferred weight reduction strategy of male individuals is to work out. It is interesting to reflect this outcome with the results of several epidemiological studies. These show, the superiority of dietary changes compared to an increase in physical activity as a weight-reducing behaviour $[12,13]$. Though, this holds for both genders the differences are more pronounced for women, likely because physical activity has been shown to be more effective in offsetting weight gain in men compared to women (e.g. [12, 22]). Thus, women seem to choose (un)consciously the more successful strategy regarding the objective 'weight loss'. However, a combined strategy of dietary change and physical activity leads to even better outcomes when it comes to weight reduction, with the combined effect being in the case of women even larger than the additive ones for each behavioural change separately (e.g. $[12,23])$. Considering our findings and the results of epidemiological studies, governmental information campaigns targeted towards women should stress the relevance of physical activity as a complementary strategy for losing weight. In parallel, campaigns directed at men should emphasise the importance of dietary adjustments in controlling weight as physical activity seems to be so far the primary strategy of men in their fight against overweight. 
Strengths of our study are the large sample size as well as the inclusion of respondents of 19 countries from different continents, covering low-, medium- and high-income countries. Limitations to this study are closely linked to this strength. Conducting a survey around the world restricts the number of questions that can be asked. For that reason the survey focused on attitudes, gender and nationality as determinants of health-conscious behaviour, though several other constructs such as preferences, perception and socio-demographics other than gender determine choice of strategy.

Future research could focus on culture-influencing attitudes, e.g., by grouping countries and including interaction effects between country groups and attitudes in the regression. Also, segmentation approaches or pattern analyses used in data mining might be useful to better account for regional effects.

\section{Conclusion}

High-income as well as low-income countries are experiencing an obesity epidemic, though considerable differences exist between and within countries. To counteract this development, it seems important to better understand how people react once their body weight goes beyond a certain threshold.

Our findings indicate that most people choose to change their dietary patterns followed by those who increase their physical activity. Only a minority chooses methods such as acupuncture for losing weight. Main results are that women are more likely to change their diets while men are more likely to become physically active. The choice of a weight reduction is significantly impacted by an individual's nationality. Finally, consumers who already carry the attitude that they are 'food lovers' are less likely to adjust dietary patterns.

For public health policies, it is vital to understand determinants of citizens' engagement in weight reduction strategies once a certain threshold is reached. Thus, results can support the design of public health campaigns and programmes that aim to change community or national health behaviour trends taking into account, e.g., gender and national differences.

\section{Disclosure Statement}

The authors declare no conflict of interest.

\section{References}

1 WHO (World Health Organization): Overweight and obesity. www.who.int/gho/ncd/risk_factors/overweight/ en/ (last accessed January 26, 2015).

2 Fontaine KR, Barofsky, I: Obesity and health-related quality of life. Obes Rev 2001;2:173-182.

-3 Dixon JB: The effect of obesity on health outcomes. Mol Cell Endocrinol 2010;316:104-108.

4 Cawleya J, Meyerhoefer C: The medical care costs of obesity: an instrumental variables approach. J Health Econ 2012;31:219-230.

-5 Withrow D, Alter DA: The economic burden of obesity worldwide: a systematic review of the direct costs of obesity. Obes Rev 2011;12:131-141.

6 Finkelstein EA, Strombotne KL, Popkin BM: The costs of obesity and implications for policymakers. Choices 2010;25(3). www.choicesmagazine.org/magazine/article.php?article=136 (last accessed January 13, 2015).

7 Yach D, Stuckler D, Brownell KD: Epidemiologic and economic consequences of the global epidemics of obesity and diabetes. Nat Med 2006;12:62-66.

8 WHO (World Health Organization): Global Strategy on Diet, Physical Activity and Health. Geneva, World Health Organization, 2004. 
Grebitus et al.: Global Obesity Study on Drivers for Weight Reduction Strategies

-9 Korthals MJJAA: Coevolution of nutrigenomics and society: ethical considerations. Am J Clin Nutr 2011;94: 2025-2029.

10 Greene WH: Econometric Analysis, 4th ed. New Jersey, USA, Prentice Hall, 2000.

-11 Olsson U: Maximum likelihood estimation of the polychoric correlation coefficient. Psychometrika 1979;44: 443-460.

12 Dunn CL, Hannan PJ, Jeffery RW, Sherwood NE, Pronk NP, Boyle R: The comparative and cumulative effects of a dietary restriction and exercise on weight loss. Int J Obes 2006;30:112-121.

13 Jakicic JM, Wing RR, Winters-Hart C: Relationship of physical activity to eating behaviors and weight loss in women. Med Sci Sports Exerc 2002;34:1653-1659.

14 Cooke L: The importance of exposure for healthy eating in childhood: a review. J Hum Nutr Diet 2007;20: 294-301.

15 Westenhoefer J: Establishing dietary habits during childhood for long-term weight control. Ann Nutr Metab 2007;46:18-23.

-16 De Sa J, Lock K: Will European agricultural policy for school fruit and vegetables improve public health? A review of school fruit and vegetable programmes. Eur J Public Health 2008;18:558-568.

17 Schwarzer R: Social-cognitive predictors of health behavior: action self-efficacy and coping self-efficacy. Health Psychol 2000;199:487-495.

-18 Schwarzer R, Schiiz B, Ziegelmann JP, Lippke S, Luszczynska A, Scholz U: Adoption and maintenance of four health behaviors: theory-guided longitudinal studies on dental flossing, seat belt use, dietary behavior, and physical activity. Ann Behav Med 2007;33:156-166.

19 Marteau TM, Ogilvie D, Roland M, Suhrcke M, Kelly, MP: Judging nudging: can nudging improve population health? BMJ 2011;342:263-265.

20 Petty RE, Cacioppo JT: Source factors and the elaboration likelihood model of persuasion. Adv Consum Res 1984;11:668-672.

21 Wardle J, Haase AM, Steptoe A: Body image and weight control in young adults: international comparisons in university students from 22 countries. Int J Obes 2006;30:644-651.

-22 Donnelly JE, Hill JO, Jacobsen DJ, Potteiger J, Sullivan DK, Johnson SL: Effects of a 16-month randomized controlled exercise trial on body weight and composition in young, overweight men and women: the Midwest Exercise Trial. Arch Intern Med 2003;163:1342-1350.

23 Foster-Schubert KE, Alfano CM, Duggan CR, Xiao L, Campbell KL, Kong A, Bain C, Wang CY, Blackburn G: Effect of diet and exercise, alone or combined, on weight and body composition in overweight-to-obese post-menopausal women. Obesity (Silver Spring) 2012;20:1628-1638. 